reassured to find out that their illness was not rubella. It is equally important that the infants of those mothers in whom the disease is virologically confirmed are followed up carefully over a prolonged period in order that early lesions may be sought. If they are present, every assistance and encouragement can then immediately be given to both the mother and her affected child. It is possible that the attenuated vaccines $^{9-11}$ which recently have been developed will go a long way to solving these problems before too long.

\section{Computers on the March}

For all the swift obedience with which computers reply to the questions put to them they remain exacting servants. Their initial costs are very high, the user may have to rearrange his working life to suit the computer he employs, and the equipment itself demands some understanding if its capabilities are to be fully brought out.

This week the B.M.A. Planning Unit publishes a report of a working party on computers in medicine. ${ }^{1}$ As well as reviewing the functions for which these instruments are suited it considers possible future applications. In this respect it is well timed to help medical men take part in the planning of computer services in their practice and administration, especially as it provides an excellent glossary of the technical terms essential to any informed discussion of these machines. Doctors need no longer puzzle over " high-level language," worry about the quality of "utility programmes," or reach for the D.D.T. when " debugging." But more important is the questioning this report should stimulate in its readers' minds on what function computers may have as adjuncts to the practice of medicine. According to the foreword many millions of pounds may be allocated for the provision of computers in the Health Service, and it comments: "This report will do little to allay the suspicions of some health service workers that the unsolicited generosity of Government in this matter may be intended primarily to serve the purposes of a national computer industry rather than the interests of the Health Service."

So far in Great Britain the computer has been set to a variety of tasks in the health services, some of which were discussed in a series of articles in the B.M.7. last year. ${ }^{2}$ They have won a place in pathology laboratories, ${ }^{34}$ proved to be exceedingly helpful in research entailing calculations on large quantities of data, improved the storage and retrieval of records, and facilitated the complex calculations needed in radiotherapy. In the monitoring of patients they find a place, and their use in hospital administration is growing. But growing too fast, according to Dr. J. H. Mitchell, who declares in his paper at page 157 this week that "the medical profession is in danger of being dazzled by optimistic claims about the usefulness of computers in case record processing."

To medical men as well as to their patients the safeguarding of professional secrecy must be paramount, and the report devotes some space to discussing its preservation if computers

1 Report of the Working Party on Computers in Medicine, British Medical Association Planning Unit Report No. 3, 1969. London, British Medical Association. Price 9s. 6d., including postage.

2 British Medical fournal, 1968, 2, 823; 3, 51;3, 116 ; 3, 180 ; 3, 247 ; 3, 309;3, 367

s Automation and Data Processing in Pathology, ed. T. P. Whitehead fournal of Clinical Pathology, 1969, Symposium Supplement No. 3, B.M.A. House.

- British Medical fournal, 1969, 3, 374.

$\checkmark$ Acheson, E. D., Medical Record Linkage, 1967. London, O.U.P. came into use to store medical information about individual patients under their names. To put various kinds of restrictions on the withdrawal of information from a computer is technically simple enough. It can thus be made available only to certain specified individuals, and this method of storing it could theoretically provide greater safeguards than exist at present. But anxiety lest the information might be subject to deliberate misuse is understandable. Could there be bank robbers working at these machines with blackmail in mind ? More cogent perhaps is the mistrust anyone may reasonably feel of governmental departments and agencies, or employers and other people in authority, learning more than was intended about a person owing to some simple oversight-or even by a change in the law. That formerly private store of personal information, a person's bank account, is now by law open to inspection by the Inland Revenue authorities. Experience with medical record linkage schemes ${ }^{5}$ so far is that the general public will co-operate, no doubt partly because the dedicated and enthusiastic doctors in charge have shown that safeguards are practicable and the scheme is for the individual's benefit. But on a scale so large that virtually the whole population would have their medical histories recorded for life in a computer-and perhaps after death too?-the official and impersonal character of the arrangements would be unlikely to enjoy the same compliance. The question would therefore have to be considered whether a person going to a doctor in the Health Service could refuse to have his record computerized.

But what must weigh heavily in any extension of computers in the health services is their high cost in relation to that of many other desperately needed improvements. The sort of equipment needed would range in price from about $£ 30,000$ for a machine doing a few specific tasks to about $£ 500,000$ for one capable of functioning more generally. Skilled staff must be employed to service it and the equipment be replaced after not very many years. The report suggests that a figure appropriate to the hospital service in this country over the next 15 years could be $£ 20$ to $£ 40$ million a year. Such figures give some basis to its comment on the financial consequences of computerization that "in practice, direct cost savings are not often demonstrable." Time certainly is saved, and this can be essential to a pathology laboratory faced with an ever growing demand for biochemical tests, for instance. And despite the bills for $£ 1$ million or so that some harassed householders claim to have received from their computerized gas boards the reduction of error is described in the report as " a very real benefit." On this, it suggests, the justification for automation may in the long run heavily depend. And the best prospect for effective use at reasonable cost and in reasonable time is " in replacing tedious, slow, and error-prone but conceptually simple human operations." This certainly cuts the computer down to size and helps to direct attention to those aspects of the management of patients where the computer can be a real aid to doctor, nurse, or clerk rather than a wonderful toy for which work must at all costs be found.

Dr. Henry Miller, introducing the report, states that if the Health Department has a policy on computers it is slow to expose it to expert examination or to public discussion. Clearly, enormous sums of public money are involved in the provision of this equipment. Staff will need to be trained to a high level of skill to operate it. Every practising doctor will need to acquire considerable understanding of what a computer service can and cannot provide, so that instruction on them will have to be offered at both under- 
graduate and postgraduate levels. A thorough investigation is needed into whether the reorganization of practice that might be needed if computers are to be used effectually would impair the personal relationship between doctor and patient on which, despite biochemical adjustments, so much good or ill health depends. Finally, what are the priorities where funds are of necessity limited ?

Whether or not it is true that " major decisions have been taken on political or commercial grounds," the practice of medicine by every individual doctor is going to be influenced in the next few years by computer developments. In guiding them correctly doctors have a responsibility to assess the needs of their patients lest real but immeasurable benefits are destroyed for the sake of false but measurable efficiency. The Government on its part has a duty to be perfectly frank with the medical profession about its plans, if any, for expanding the computer services, for unless the great variety of need that medical practice fulfils is adequately understood they could prove to be an expensive failure.

\section{Journal for Psychiatric Research}

In the autumn of next year the B.M.A. proposes to launch a new journal for the publication of research in clinical psychiatry and the sciences related to it. It will be one of the Association's group of specialist journals, and appear, at first quarterly, under the title "Psychological Medicine" - a term chosen for the breadth of its connotation, and also for the hint it provides on the journal's country of origin. The editor will be Professor Michael Shepherd, who holds the chair of epidemiological psychiatry at the Institute of Psychiatry, London University, assisted by Dr. J. L. Gibbons and Professor K. Rawnsley, and supported by a large and notably broadly based editorial board ${ }^{1}$ which, besides psychiatrists, includes experts in psychology, sociology and social medicine, pharmacology and neurophysiology, child development, genetics, and statistics.

Speed in publication is what every research worker wants, and those engaged in psychiatry are no exception. Since the war their number has multiplied, and the relevance of their discipline for nearly every branch of clinical medicine is now almost universally conceded. Yet, when there is already so much to read, the launching of any new journal-even in so wide and important a field-requires some justification. Examination of the current situation in Britain makes it clear there is a need. Our two major journals concerned with general psychiatry are the fournal of Neurology, Neurosurgery, and Psychiatry, which is published by the B.M.A., and the British Fournal of Psychiatry. For some years the "Green Journal," as the former is known, has been understandably weighted towards the neurological end of the neuropsychiatric spectrum, and, as in other countries, it is now evident that a single journal can no longer encompass both disciplines. Since the fournal of Mental Science underwent its metamorphosis into the British Fournal of Psychiatry

${ }^{1}$ Dr. G. W. Ashcroft, Dr. J. A. N. Corsellis, Dr. J. W. B. Douglas, Professor J. G. Gibson, Professor D. V. Glass, Professor H. Gwynne Jones, Professor G. W. Harris, Dr. M. Lader, Professor Sir Aubrey Lewis, Dr. W. A. Lishman, Professor W. M. Millar, Professor W. D. M. Paton, Professor L. S. Penrose, Dr. Cyril Rashbass, Dr. Geoffrey Rose Dr. G. F. M. Russell, Dr. M. L. Rutter, Dr. Peter Sainsbury, Dr. F. Kraüpl Taylor, Professor J. Tizard, Dr. Ian Sutherland, Dr. J. K. Wing, and Professor O. C. Zangwill. in 1963 its new format has won general approval, but this journal is published by authority of its parent association, the Royal Medico-Psychological Association, and the pressure on its space is considerable. At the same time the recent growth of academic departments of psychiatry has led to a large increase in the output of research. Many workers in Britain are already having to publish their papers abroad, and the supply of papers is certain to increase during the next decade. These are cogent reasons for a British-based psychiatric journal for the rapid publication of scientific work in clinical psychiatry or any of the several basic sciences related to it.

Progress in psychiatry depends on advances in a great many disciplines, and Professor Shepherd discusses some of them in an article printed at p. 161 of this issue of the B.M.F. For too long psychiatry has had the unenviable reputation of being a battleground for warring factions of fanatical enthusiasts. Happily these days are passing, and the new journal is a further sign of this. For fresh advances here, as in so many branches of medicine today, must increasingly depend on collaboration between workers of very varied training and experience. It is to serve their needs, especially, that Psychological Medicine is being started. The first issue is planned for November 1970, and manuscripts for it may now be submitted, addressed to the Editor, Psychological Medicine, B.M.A. House, Tavistock Square, London W.C.1.

\section{Overseas Aid}

Britain has for long been active in contributing to the medical needs of the developing countries. Indeed, in the aggregate she has probably done more than any other nation in this field. Much of the stimulus for this arose from colonial responsibilities. These have nearly all ended, but they have created obligations of a different kind that remain.

However great the medical deficiencies of a developing country may be, Britain recognizes that the advice and help given to it must be given in the form requested. ${ }^{1}$ The best and most economical way of helping the developing countries to improve their medical services is to raise the standards of teaching at their own teaching centres and to train their own teachers, so that this central influence may permeate the whole of their medical systems. But while it is essential to recognize the sovereignty of developing countries much can be done by wise advice to help them get their priorities right. There is in all countries at all stages of development a natural preoccupation with curative medicine, usually to the detriment of preventive medicine. Sick people are insistent in their demand for prompt individual medical aid, and in a democratic society this places relatively impersonal preventive measures at a disadvantage in popular esteem. But clean water, sound conservancy, high immunization states, control of the vectors of disease, and adequate nutrition have greater value to the community than dispensaries and hospitals. It is for this reason that Britain's programme of aid places considerable emphasis on technical measures of a preventive nature.

The most useful form of assistance is in the provision of trained staff. Apart from those medical men and women

\footnotetext{
1 Britain and the Developing Countries: Health. Central Office of Information Reference Pamphlet 88. H.M.S.O.

2 Partners in Development, 1969, Report of the Commission on International Development. London, Pall Mall Press.
} 